\title{
Field survey and UAV remote sensing as tools for evaluating the canopy management effects in smallholder grapevine farm
}

\author{
Elena Brunori ${ }^{1,}$, , Federico Valerio Moresi ${ }^{1}$, Mauro Maesano ${ }^{1}$, Matteo De Horatis ${ }^{2}$, Riccardo Salvati ${ }^{3}$, Giuseppe \\ Scarascia Mugnozza ${ }^{1}$ and Rita Biasi ${ }^{1}$ \\ ${ }^{1}$ DIBAF. Department for Innovation in Biological, Agro-food and Forest systems, University of Tuscia, 01100 - Viterbo Italy. \\ ${ }^{2}$ De Horatis, Link Campus University, Via del Casale di S. Pio V, 00165 Rome, Italy. \\ ${ }^{3}$ Presidential Estate of Castelporziano, Via Pontina 690, 00128 Rome, Italy.
}

\begin{abstract}
The transition towards more resilient and sustainable agricultural systems must start from smallholder farms (SHs), that are responsible for one third of total crop production, are crucial to preserve ecosystems services, but are restive to adopt precision viticulture (PV) tools because benefits are considered insufficient to justify the costs. PV could help SHs to face with climate variability, maintaining high quality standards in the vineyard and to increase grapevine resilience adopting strategic cultural practices. This paper focus on evaluating some canopy management techniques (leaf removal at different phenological stages) on Italian grapevine landraces through field survey and UAV remote sensing, to obtain an automated estimation of the vine status in terms of canopy architecture, vine vigour, and berry traits. Findings showed as the adoption of canopy management practices, like the leaf removal, can increase the productive performance of the vines by regulating canopy growth, improving berry quality, and at the same time can increase the environmental sustainability of viticulture. Remote sensing restores a real-time vegetational indices (VIs) at vine scale that SHs could use to maximize quality and sustainability through a more efficient and site-specific management of the vineyard.
\end{abstract}

\section{Introduction}

The growing interest in precision viticulture (PV) comes from the need to maintain high quality standards in the vineyard and to re-think vineyards management practices towards a sustainable intensification approach. This implies the adoption of differentiated management approaches and/or site-specific strategies [1]. The transition towards more resilient and sustainable agricultural systems must start from smallholder farms (SHs) that represent globally the $84 \%$ of farming households and $67 \%$ in EU [2]. SHs are responsible for one third of total crop production. They are crucial stewards of biodiversity and significant in provisioning ecosystem services, in mediating social outcomes that are relevant to sustainable development $[3,4]$. However, they are restive to adopt PV because benefits are considered insufficient to justify the costs [5]. In Italy, $\mathrm{SHs}$ in the grape-wine sector are operating on small vineyards (average extension 1 hectare) located in highly varied topography, climatic features, landform, and landscapes [6], bases of the concept of terroir and wine diversification. In this context, the application of PV based on the use of unmanned aerial vehicles (UAVs) and high resolution image may result in monitoring and managing the spatial variability of vigour status [7], canopy architecture, phenotyping knowledge, yield and berry quality, soil traits, water and nutrient availability, providing geolocated data for real-time vegetational index (VIs) mapping [8-12].

\footnotetext{
Corresponding author: brunori@unitus.it
}

VIs combines two or more spectral bands - e.g. linked to properties of photosynthetic pigments in plants leaves - in a mathematical formulas and can be used for better manage the vineyard when combined with precision agriculture techniques, therefore improving vineyard management efficiency in terms of berry quality, yield and environmental sustainability [13-15]. Furthermore, innovative cultural practices have been proposed for mitigating climate change effects and for preserving yield and berry quality [16], like leaf removal (LR). This practice has been studied as a strategic canopy management tool to address and improve vine performance and pest control under different environmental conditions [17]. Since it affects directly the architecture of the canopy and indirectly the microclimate and the berry quality, this study aimed at an automated estimation of the vine status in terms of canopy architecture, vine vigour, and berry traits under different canopy management practices (leaf removal), by employing high resolution RGB images (20 MP) taken with a low-cost UAV platform in a SHs vineyard of landraces of central Italy (Montefiascone, Latium Region). 


\section{Material and methods}

\subsection{Study area and experimental design}

The study area is located in the southern part of Bolsena lake basin in Central Italy (Latium region, figure 1). Vines (25-year-old) in rainfed tested vineyard are spaced $1.5 \mathrm{~m}$ within row and $3.0 \mathrm{~m}$ between rows and are trained to a vertical shoot positioning spur-pruned cordon with eight/ten buds per vine; each single row is dedicated to conservation of one local cultivar. The study was carried out during the season 2016 on three rows and therefore three varieties: two landraces Cannaiola di Marta (CM) (Code IVD-var_9; Italian Vitis Database. www.vitisdb.it) and Rossetto (RO) (Code IVD-var_217; www.vitisdb.it) - respectively red and white berry varieties, and an international variety Cabernet sauvignon (CS).

The experimental design was a randomized complete block with four canopy management treatments per cultivar. Each row (one per cultivar) was divided in four identical blocks per number of vines; leaf removal treatments were applied in accordance to crucial phenological stages of grape berry development [18]. The treatments planned were: (1) early leaf removal (LR1) applied at full flowering - 50\% of flower hoods fallen (BBCH 065); (2) post-veraison leaf removal (LR2) performed at beginning of ripening: berries begin to develop variety - specific colour (BBCH 081); (3) preharvest leaf removal (LR3) applied at softening of berries (BBCH 085); and (4) no leaf removal (ordinary canopy management - control C). For all LRs, the basal six leaves of all fruiting shoots were removed manually [17] (figure 1). Within each treatment, three clusters of three consecutive vines were selected as representative (nine vines per block). Field measurement and canopy microclimate monitoring were performed only on the central vine, while the other ones were served as a buffer [19] (Figure 1).

\subsection{Canopy microclimate monitoring}

Temperature and humidity probes contained in a watertight case with IP 67 protection were placed on a support inside the vine canopy, at the bunches level for each treatment (LR1, LR2, LR3 and C). The sensors acquired the temperature minimum, medium and maximum values every 30 minutes. Data were recorded and transmitted to informatic platform and stored.

\subsection{Canopy architecture characterization}

The average leaf area for the main and lateral shoots was measured at the end of shoot growth. For this purpose, three leaves per each tested shoot and for each treatment were harvested and the leaf area detected by a digital camera and measured by ImageJ 2 software [20]. Total leaf area per main and lateral shoots $\left(\mathrm{cm}^{2} \cdot \operatorname{shoot}^{-1}\right)$ and total Leaf Area Index (LAI; $\mathrm{m}^{2}$ leaf area $\cdot \mathrm{m}^{-2}$ soil) [21] were derived, based on the main and lateral shoot number and leaf average area [23]. Three class of brightness, based on Beer's Law and useful to detect the transmission of light though the canopy, were detect: white, light green, and dark green. Appling this analysis algorithm allowed to calculate the canopy porosity based on gap analysis [24] and as showed in formula 1.

Porosity (\%) $=T g / T p$

where: $\mathrm{Tg}$ is the total pixel gaps (white pixel brightness) and $\mathrm{Tp}$ is the sum of all pixels (white, light green and dark green). Moreover, the canopy thickness after segmentation process of the RGB images was determined.

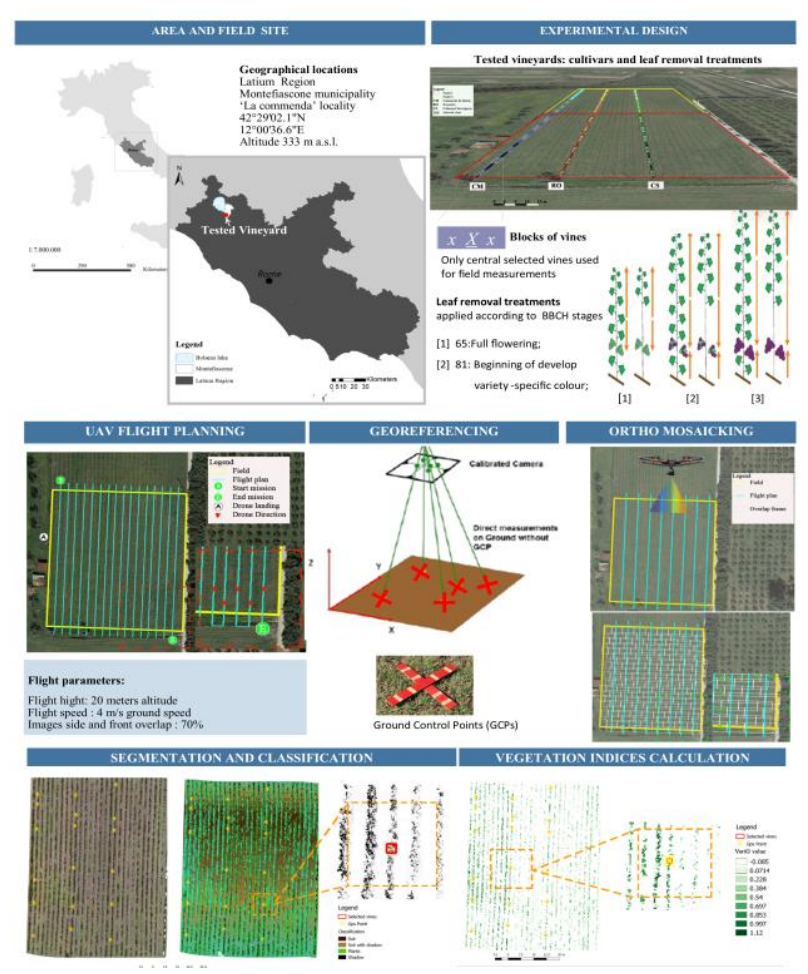

Fig. 1. Geographical locations of the tested vineyard and schematic representation of the experimental design for leaf removal treatments and for field measurements. Unmanned Aerial Vehicle (UAV) campaigns flight planning, georeferencing methods, RGB images processing procedures, example of vegetational index (VI) map.

\subsection{UAV campaigns}

The UAV campaigns were performed by a six-rotor multi-rotor UAV (DJI MATRICE 600) equipped by RGB sensor (Zenmuse X5). RGB photos were acquired in sunny weather at midday; the flight characteristics are showed in figure 1. Ten ground control points (GPs) were placed into the vineyard and used for georeferencing images by QGIS open-source software. The coordinates of the GCPs were relieved through a differential GNSS (Leica CS10 GNSS, Leica Geosystems AG) with accuracy of $0.01 \mathrm{~m}$. Drone Deploy (blog.dronedeploy.com) open-source software was used for ortho-rectification of the photos and for creating orthomosaics. Boolean logic for the classification in ECognition software (Trimble Geospatial) was used to extract the sample vines for each 
treatment from orthomosaics, for calculating the Vegetation Indices (VIs).

\subsection{Vegetation indices (VIs) for Visual Data}

The digital number (DN) values for the red, green, and blue channels of each treatment plot were extracted for calculating the vegetation indices (VIs). Three VIs have been selected in the visible light spectrum, including Visible Atmospherically Resistant Index (VARI), Normalized Difference Greenness Vegetation Index (NDGI), and Red Green Ratio Index (RGRI) [25].

\subsection{Vine balance and berry quality indices}

At harvest time, for selected vines of each canopy treatment, the number of bunches per vine was recorded, three bunches were picked and weighted, and the number of berries per bunch were counted; for each berry weight, volume and surface were defined; moreover, the total leaf area $\left(\mathrm{m}^{2}\right)$ and fruit mass $(\mathrm{kg})$ were recorded and used to calculate the leaf area to fruit mass ratio (LA:FM), [26]. Furthermore, three replicates of juice obtained from randomly picked berries (99 berries dived into three replicates) were analysed.

The indices used to evaluate the berry quality were: (a) total soluble solids (TSS - ${ }^{\circ}$ Brix) using a digital refractometer (DBR 35 Salt); (b) titratable acidity (A $\mathrm{mg} / \mathrm{L}$ of tartaric acid) - drawing 50 millilitres (ml) of juice into in a vacuum flask for $\mathrm{CO}_{2}$ elimination before the potentiometric titration with sodium hydroxide solution, $0.1 \mathrm{~mol} / \mathrm{L}$, until the $\mathrm{pH}$ is equal to 7 at $20^{\circ} \mathrm{C}$, according to Compendium of international methods of analysis (OIV-MA-AS313-01); and (c) total polyphenols $(\mathrm{PFT}-\mathrm{mg} / \mathrm{L})$ and total anthocyanins (ANT $-\mathrm{mg} / \mathrm{L})$ in grape berries using an OenoFoss ${ }^{\mathrm{TM}}$ analyser (FOSS Analytical A/S, Denmark).

\subsection{Statistical analysis}

All determinations were carried out in three replicates and all analytical results were subjected to a statistical analysis performed at the $\mathrm{p}<0.05$ significance level and carried out by XLSTAT using one-way ANOVA and Fisher's LSD test. Correlation matrix (Pearson's coefficient) was used to identify variables close-related to each other. A Principal Component Analysis (PCA) was carried out using all variables and indices to detect the effect of the timing of leaf removal on canopy structure, berry chemical and physical traits.

\section{Results and discussion}

Leaf removal affected canopy microclimate, structure and, consequently, the berry quality traits. Depending on the leaf removal treatment, daily thermal range (Figure 2) within the vine canopy showed different dynamics. It has been recognized that LR increases light irradiance available to the fruit zone, air speed within the canopy and consequently changes the microclimate close to clusters zone, mainly temperature, that is considered determining factor in regulating grapevine sensitivity response to heat stress [27]. LR1 enhanced the daily thermal range at harvest time, and berries were direct sun-light exposed during the first part (June) of berry growth stages. Late LR treatments, at post-veraison (LR2) and pre-harvest (LR3) stages, exhibited the highest temperature in the cluster zone of the canopy, nearby to harvest date, as consequence of absence of leaves around the bunches in the hottest month of the year, e.g LR2. exposed berry to higher maximum temperature than LR1 and $\mathrm{C}\left(+2.4\right.$ and $1.9{ }^{\circ} \mathrm{C}$, respectively). LR treatments affected foliage traits and canopy architecture and structure.

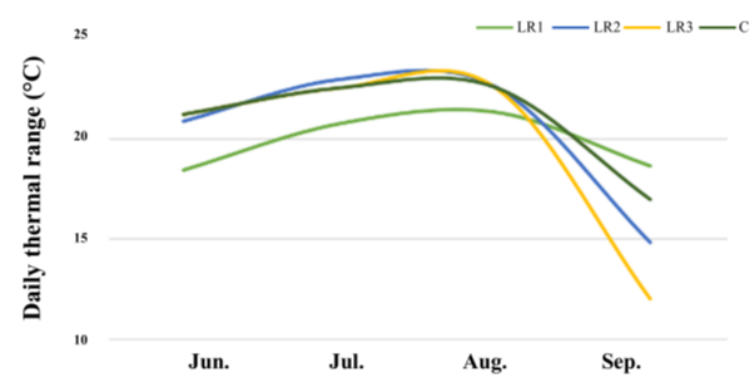

Fig. 2. Daily thermal range dynamics related to $L R$ and $C$ treatments for 2016 season for cv. Cabernet Sauvignon. (LR1: early leaf removal - BBCH 065; LR2: post-veraison leaf removal - BBCH081; LR3 _ pre harvest leaf removal $\mathrm{BBCH} 085$ and $\mathrm{C}$ : control, ordinary canopy management).

Leaf removal treatments did not affect the lateral shoot development, but they reduced leaf area. LR1 treatment applied on the red grape varieties caused a reduction of LAI respect to control (C) by $16 \%$ and $18 \%$ for CM and CS respectively; LR2 reduced LAI of CM and $\mathrm{CS}$ by $23 \%$ and $1 \%$, respectively. On the white variety, LAI reduction respect to $\mathrm{C}$ was $8 \%$ in LR1, $19 \%$ in LR2 and 3\% in LR3.

As regard the canopy porosity, the analysis showed significant difference in all cvs revealing an increment in early leaf removal treatment (LR1) compared to other ones (Figure 3). Porosity was greater in LR1 treatment, and the lowest values were recorded for LR2 and LR3.

Interesting information were derived from the vegetation indices obtained by UAV- based visible images analysis, able to assess the outcome of canopy management practices. Findings showed (Figure 4) as performant VIs such as VariG, canopy porosity and RgRi performed by high resolution RGB images taken with a low-cost UAV platform could be able to predict at single plant scale the spatial and temporal variability in field applying canopy practices (leaf removal) equal to NIR-based VIs [28].

In addition, they showed close relation with vine and berry traits and could be key tools to preserve vine status (yield and health) and berry physical and chemical quality. LR treatments lead to a different bunch structure. LR1 reduced bunch compactness, that could contribute to decrease susceptibility to pests and diseases and impact on ripening rate and berry composition [29]. 
LR treatments caused a change in leaf area to fruit mass ratio (LA:FM) (Table 1). LAI reduction affected crop load reducing the bunch weight by reducing of berry volume and weight [17] and consequently affected berry quality in both physical than chemical traits [30] and harvest date. In fact, differences were found between technological and phenolic maturity at harvest times for all $c v s$ and all treatments. Total soluble solids and total acidity of berries of LR vines showed - respectively higher and lower values compared to berries of control vines. The phenolic components also showed significant differences. PFT content in CM was higher for LR3 and LR1 than for C and LR2; in CS their content reached a higher value for LR1 and C. ANT reached greater values in berries of LR1 treatment, while LR3 concurred heavily to reduce them.

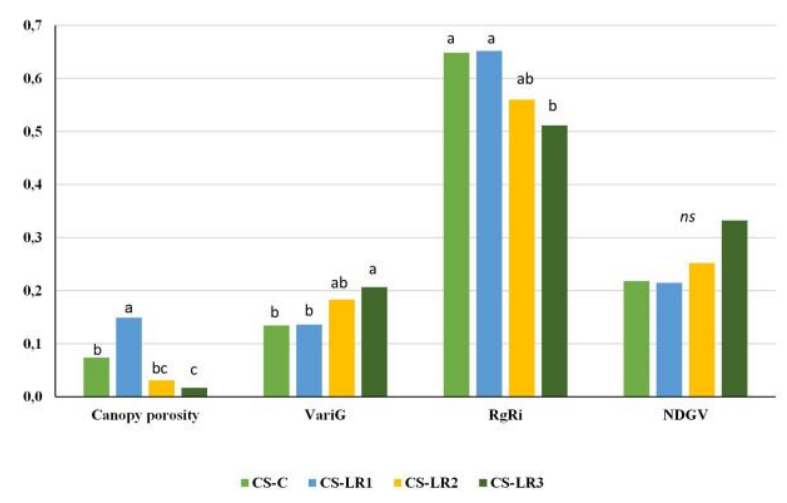

Fig. 3. Canopy porosity, VIs and significantly differences at $p$ $<0.05$ among cvs and canopy treatment (LR1: early leaf removal - BBCH 065; LR2: post-veraison leaf removal BBCH081; LR3_ pre harvest leaf removal - BBCH085 and C: ordinary canopy management).

Table 1. Leaf area to fruit mass ratio: (LA:FM) and berry quality traits (berry volume: BV; total solids soluble: TSS; titratable acidity: total antocyanins poliphenols: PFT) for vines of the cvs Cabernet sauvignon (CS), Roscetto (RO) and Cannaiola di Marta (CM) under different leaf removal (LR) treatments (C: Control; LR1: early leaf removal; LR2: postveraison leaf removal; LR3: pre-harvest leaf removal).

\begin{tabular}{|c|c|c|c|c|c|c|c|c|c|c|c|c|c|c|}
\hline \multicolumn{2}{|c|}{$\begin{array}{l}\text { Varieties } \\
\text { Treatments } \\
\end{array}$} & \multicolumn{4}{|c|}{$\begin{array}{l}\text { LA:FM } \\
\left(\mathrm{m}^{2} \cdot \mathrm{kg}^{-1}\right)\end{array}$} & \multicolumn{3}{|c|}{$\begin{array}{l}\text { BV } \\
(\mathrm{ml})\end{array}$} & \multicolumn{3}{|c|}{$\begin{array}{c}\text { TSS } \\
\left({ }^{\circ} \text { Brix) }\right. \\
\end{array}$} & \multicolumn{3}{|c|}{$\begin{array}{c}\text { PFT } \\
\left(\mathrm{mg} \cdot \mathrm{L}^{-1}\right) \\
\end{array}$} \\
\hline \multirow{4}{*}{$\mathrm{CM}$} & $\mathrm{C}$ & 4.2 & \pm & 1.2 & $a b$ & 2.1 & & & 24.9 & \pm 0.1 & $a$ & 775.3 & \pm 5.3 & $b$ \\
\hline & LR1 & 8.5 & \pm & 1.8 & $b$ & 1.8 & \pm & & $22.8=$ & \pm 0.1 & $b$ & 815.9 & \pm 4.1 & $c$ \\
\hline & LR2 & 9.6 & \pm & 3.6 & $a b$ & 1.9 & \pm & & 23.0 & \pm 0.1 & $b$ & 742.8 & \pm 12.1 & $d$ \\
\hline & LR3 & 11.3 & \pm & 4.7 & $a$ & 1.6 & \pm & & $23.7=$ & \pm 0.1 & $b$ & 987.8 & \pm 10.8 & $a$ \\
\hline \multirow{4}{*}{ RO } & $\mathrm{C}$ & 20.7 & \pm & 5.5 & $a$ & 1.8 & \pm & & $25.3=$ & \pm 0.1 & $a$ & 839.5 & \pm 57.3 & $a$ \\
\hline & LR1 & 18.9 & \pm & 5.8 & $a$ & 1.6 & \pm & & 21.4 & \pm 0.1 & $b$ & 716.4 & \pm 48.6 & $b$ \\
\hline & LR2 & 14.6 & \pm & 2.7 & $a b$ & 1.7 & \pm & & 20.8 & \pm 0.1 & $b$ & 597.5 & \pm 46.7 & $c$ \\
\hline & LR3 & 8.8 & \pm & 3.4 & $b$ & 1.4 & \pm & & 20.9 & \pm 0.0 & $b$ & 626.0 & \pm 52.7 & $c$ \\
\hline \multirow{4}{*}{ CS } & C & 18.5 & \pm & 1.5 & $a$ & 2.1 & \pm & & $23.9=$ & \pm 0.1 & $a$ & 951.9 & \pm 27.1 & $a$ \\
\hline & LR1 & 13.0 & \pm & 7.8 & $a b$ & 1.8 & \pm & & 22.9 & \pm 0.1 & $b$ & 797.1 & \pm 5.5 & $b$ \\
\hline & LR2 & 7.0 & \pm & 0.8 & $b$ & 1.9 & \pm & & $20.2=$ & \pm 0.1 & $c$ & 374.1 & \pm 3.7 & $d$ \\
\hline & LR3 & 13.8 & \pm & 4.5 & $a b$ & 1.6 & \pm & & $23.0=$ & \pm 0.1 & $a b$ & 592.9 & \pm 7.6 & $c$ \\
\hline
\end{tabular}

Different letters indicate significantly differences at $\mathrm{p}<0.05$.

Principal components (F1, F2) explained $57.66 \%$ of the total variation (measured by the inertia), the distribution of loading factors and scores (Figure 5) in the plane spanned by the F1 and F2 pointed out a 'cvs effects'. All treatments applied to each cultivar led off into a defined quadrant. A close relationship existed between LA:FM ratio and some VIs. It exhibited strong Person's correlation coefficient (-0.8) with RDRI and whit number of berries per bunch (0.5). Among VIs, Porosity is positively close to berry quality traits. The 'cvs effects' for red varieties explained the opposite behaviour of CM and CS to LR treatments, related to berry quality traits. On the other hand, LR treatments affected greater the canopy architecture of RO [30]. All those aspects are difficult to manage in small-holder farmers characterized by highly environmental variability (soil, exposure, microclimate, landform, landscape, etc) ad generally based on local several grapevine varieties.

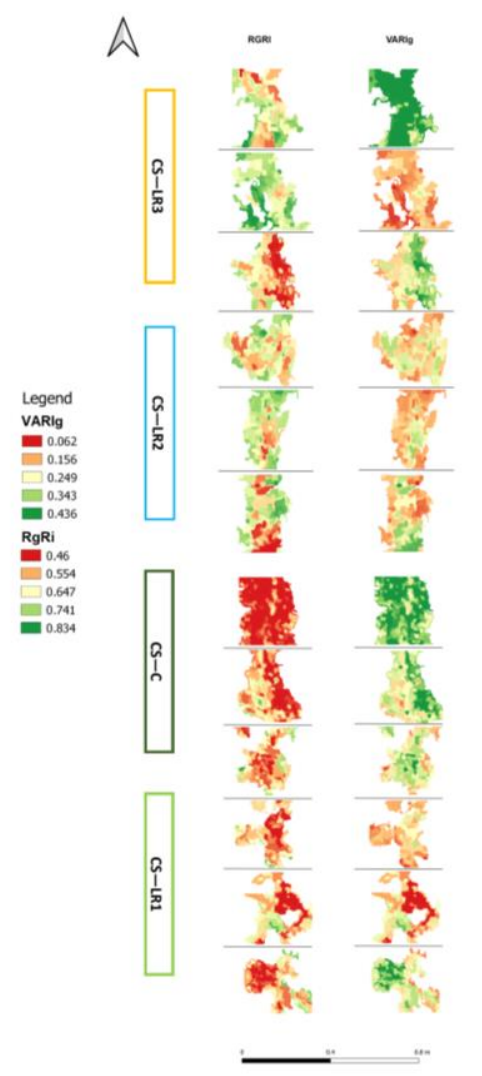

Fig. 4. VARIg and RgRi indices determined for the cv Cabernet sauvignon (CS) under different canopy treatments (LR1: early leaf removal - BBCH 065; LR2: post-veraison leaf removal - BBCH081; LR3 _ pre harvest leaf removal $\mathrm{BBCH} 085$ and C: ordinary canopy management).

\section{Conclusion}

The study showed that the adoption of canopy management practices, like the leaf removal, can increase the productive performance of the vines by regulating canopy growth, improving berry quality, concurring at the same time to increase the environmental sustainability of vineyard systems. Alongside vineyard management practices, small holder farmers need to increase their competitiveness starting from a higher quality standard in the vineyard. Crucial 
key is the exhaustive renewing of viticulture focusing on different form of digitalization: Smart Farming, Precision viticulture, Digital viticulture, Viticulture 4.0 that could maximize quality and sustainability through a more efficient management at vine scale.

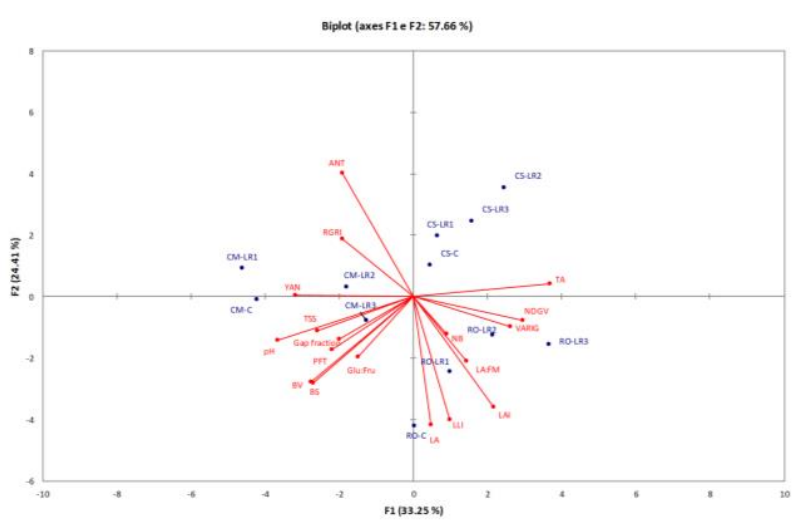

Fig. 5. Bi-plots of PCA performed by vegetation indices (VariG, RGRI and NDGV), canopy porosity and other canopy architecture traits ( leaves area: LA, leaf area index: LAI, leaf layer index: LLI; leaf area to fruit mass ratio: LA:FM; and berry quality parameters (berry volume: BV; berry surface: BS; number of berry per bunch: NB; total solids soluble: TSS; $\mathrm{pH}$; titratable acidity: TA, glucose:fructose ratio: glu:fru; yeast assimilable nitrogen: YAN; total antocyanins and poliphenols: ANT and PFT) for cvs Cabernet sauvignon (CS), Roscetto (RO) and Cannaiola di Marta ( CM) under different treatments (C: Control; LR1: early leaf removal; LR2: post-veraison leaf removal; LR3: pre-harvest leaf removal).

\section{References}

1. COM (2019) 640 final. COMMUNICATION FROM THE COMMISSION. The European Green Deal Brussels, 11.12.2019.

2. D.R. Kanter, A. R. Bell, and S.S. McDermid. O Earth (2019) 1(3):281-284.

3. V. Ricciardi, Z. Mehrabi, H. Wittman, D. James, N.Ramankutty. Nat. Sustain. (2021) 4, 651-657 ;

4. R. Biasi, R. Farina, E. Brunori. Sustain. (2021) 13 (7), 3967.

5. P.A. Galindo, C. Granell, P.G. Molin, J.H. Guijarro. Precis. Agric. (2012) 13, 594-610.

6. M. Marchetti, M. Soldati, V. Vandelli - Landscapes and landforms of Italy (pp. 7-20). Springer, Cham.

7. R. P. Sishodia, R. L. Ray, S. K. Singh. Remote Sens. (2020) 12(19), 3136.

8. J. Campos, J. Llop, M. Gallart, F. García-Ruiz, A. Gras, R. Salcedo, E. Gil, E. Precis. Agric. (2019) 20(6), 1136-1156.

9. B. Tivoli, A. Calonnec, B. Richard, B. Ney, D. Andrivon, D. Eur. J. Plant Pathol. (2013) 135(3), 471-478.

10. C. Zhang, A. Marzougui, S. Sankaran. Comput Electron Agric (2020)175, 105584.

11. M.P. Diago, B. Ayestarán, Z. Guadalupe J. Sci. Food Agric. (2012) 92(4), 925-934.
12. A. Hall, J. Louis, D. Lamb. Comput. Geosci (2003) 29(7), 813-822.

13. C. Fernández-Quintanilla, J.M. Peña, D. Andújar, J. Dorado, A. Ribeiro, F. LópezGranados. Weed Res.(2018) 58(4):259-272.

14. R. Giovos, D. Tassopoulos, D. Kalivas, N. Lougkos, A. Priovolou. Agric. (2021) 11(5), 457.

15. G. Crucil, F. Castaldi, E. Aldana-Jague, B. van Wesemael, A. Macdonald, K. Van Oost. Sustain. (2019) 11(7), 1889.

16. S. Bernardo, L.T. Dinis, N. Machado, J. Moutinho-Pereira. Agron. Sustain. De.v (2018). 38(6), 1-20

17. S.Poni, F. Bernizzoni, S, Civardi, N. Libelli. Aust. J. Grape Wine Res. (2009) 15(2), 185193.

18. D.H. Lorenz, K.W. Eichhorn, H. Bleiholder, R. Klose, U. Meier, E. Weber Aust. J. Grape Wine Res. (1995) 1(2).

19. B. Basile, G. Caccavello, M. Giaccone, M. Forlani. Am J Enol Vitic (2015) 66: 234-243.

20. C.T. Rueden, J. Schindelin, M.C. Hiner, B.E. DeZonia, A. E., Walter, E.T. Arena, K.W. Eliceiri. BMC bioinform (2017) 18(1), 1-26.

21. E. Brunori, R. Farina, R, Biasi. Agric. Ecosyst. Environ. (2016) 223: 10-21.

22. G. Pergher, R. Petris, R. J. Agric. Eng. (2007) 38(2), 31-38.

23. R. De Bei, S. Fuentes, M. Gilliham, S. Tyerman, E. Edwards, N. Bianchini. Sens. (2016) 16 (4),58

24. F. Chianucci, U. Chiavetta, A. Cutini. iForestBiogeosci. Forest. (2014) 7(4), 255.

25. E. Brunori, M. Maesano, F.V. Moresi, A. Antolini, A. Bellincontro, R. Forniti, R. Biasi, F. Mencarelli. J. Sci. Food Agric e (2020) 100(12), 4531-4539.

26. A.K. Parker, R.W. Hofmann, C. van Leeuwen, A.R. McLachlan, M.C. Trought. Aust. J. Grape Wine Res. (2014) 20(3), 422-431.

27. D. H., Greer, C. Weston. Funct Plant Biol (2010) 37(3), 206-214

28. P. Marques, A. Sousa, N. Guimarães, T.O Adão, L. Pádua, J.J. Sousa, E.P. Correia, E. P. Agron. (2019) 9, 581.

29. J. Tello, J. Ibáñez, Aust. J. Grape Wine Res. (2018) 24(1), 6-23.

30. A.K. Parker, R.W. Hofmann, C. van Leeuwen, A.R. McLachlan, M.C. Trought. Aust. J. Grape Wine Res. (2015) 21(2), 266-276. 